\title{
When the Earth Trembles in the Americas: The Experience of Haiti and Chile 2010
}

\author{
R. Vanholder ${ }^{a}$ D. Borniche ${ }^{b, c} \quad$ S. Claus ${ }^{d} \quad$ R. Correa-Rotter ${ }^{e} \quad$ R. Crestani ${ }^{f}$ \\ M.C. Ferir ${ }^{f} \quad$ N. Gibney ${ }^{g} \quad$ A. Hurtado ${ }^{h} \quad$ V.A. Luyckx ${ }^{i} \quad$ D. Portillaj $\quad$ S. Rodriguez ${ }^{k}$ \\ M.S. Sever' J. Vanmassenhove ${ }^{m}$ R. Wainstein ${ }^{\text {n }}$ \\ ${ }^{a}$ Nephrology Section, Department of Internal Medicine, Ghent University Hospital, Ghent, Belgium; \\ ${ }^{\mathrm{b}}$ Rouen University Hospital, and ' Nephrology Department, Dialysis Unit, Bois Guillaume Hospital, Rouen, France; \\ ${ }^{\mathrm{d}}$ Nephrology Section, Department of Internal Medicine, Ghent University Hospital, Ghent, Belgium; \\ e Department of Nephrology and Mineral Metabolism, Instituto Nacional de Ciencias Médicas y Nutrición Salvador \\ Zubirán, Mexico City, Mexico; ${ }^{\mathrm{f}}$ Médecins Sans Frontières, Brussels, Belgium; ${ }^{9}$ Division of Critical Care Medicine,

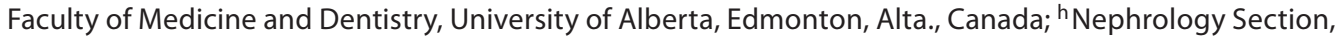 \\ Arzobispo Loayza General Hospital, Cayetano Heredia Peruvian University, Lima, Peru; 'Division of Nephrology,

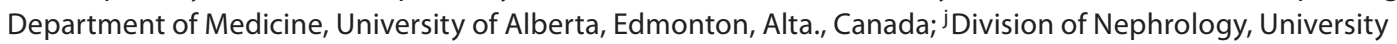

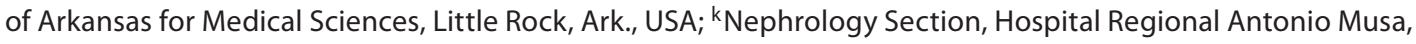 \\ Universidad Central del Este, Santo Domingo, Dominican Republic; 'Department of Internal Medicine and \\ Nephrology, Istanbul School of Medicine, Istanbul, Turkey; ${ }^{\mathrm{m}}$ Nephrology Section, Department of Internal Medicine,

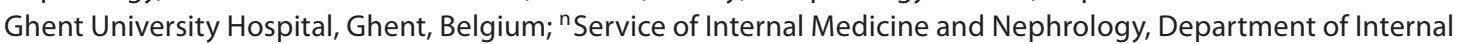 \\ Medicine, Hospital Militar de Santiago, University of the Andes and Valparaiso, Santiago, Chile
}

\section{Key Words}

Crush syndrome $\cdot$ Dialysis $\cdot$ Acute kidney injury

\begin{abstract}
The response of the nephrological community to the Haiti and Chile earthquakes which occurred in the first months of 2010 is described. In Haiti, renal support was organized by the Renal Disaster Relief Task Force (RDRTF) of the International Society of Nephrology (ISN) in close collaboration with Médecins Sans Frontières (MSF), and covered both patients with acute kidney injury (AKI) and patients with chronic kidney disease (CKD). The majority of AKI patients (19/27) suffered from crush syndrome and recovered their kidney function. The remaining 8 patients with AKI showed acuteto-chronic renal failure with very low recovery rates. The intervention of the RDRTF-ISN involved 25 volunteers of 9 nationalities, lasted exactly 2 months, and was characterized by major organizational difficulties and problems to create awareness among other rescue teams regarding the
\end{abstract}

availability of dialysis possibilities. Part of the Haitian patients with AKI reached the Dominican Republic (DR) and received their therapy there. The nephrological community in the DR was able to cope with this extra patient load. In both Haiti and the DR, dialysis treatment was able to be prevented in at least 40 patients by screening and adequate fluid administration. Since laboratory facilities were destroyed in Port-au-Prince and were thus lacking during the first weeks of the intervention, the use from the very beginning on of a point-of-care device (i-STAT ${ }^{\circledR}$ ) was very efficient for the detection of aberrant kidney function and electrolyte parameters. In Chile, nephrological problems were essentially related to difficulties delivering dialysis treatment to CKD patients, due to the damage to several units. This necessitated the reallocation of patients and the adaptation of their schedules. The problems could be handled by the local nephrologists. These observations illustrate that local and international preparedness might be life-saving if renal problems occur in earthquake circumstances.

Copyright $\odot 2010$ S. Karger AG, Basel

Raymond Vanholder

Nephrology Section, University Hospital

De Pintelaan 185

BE-9000 Gent (Belgium)

Tel. +32 9332 4525, Fax +32 9332 4599, E-Mail raymond.vanholder@ugent.be 


\section{Introduction}

On Tuesday, January 12, 2010, at $16.53 \mathrm{~h}$ local time (21.53 h GMT), a 7.0 earthquake struck Haiti (fig. 1a). The epicenter was located in Léogâne, $25 \mathrm{~km}$ west of the densely populated (3,000,000 inhabitants) Port-au-Prince metropolitan area. More than 220,000 people died and more than 310,000 were wounded. Less than 2 months later, an 8.8 earthquake affected the Maule region in Chile on February 27, 2010 (fig. 2).

The Renal Disaster Relief Task Force (RDRTF) of the International Society of Nephrology (ISN) offers nephrological support in mass disasters, essentially massive earthquakes where a large number of patients develop acute kidney injury (AKI) due to rhabdomyolysis and crush syndrome [1-4]. In some cases, such as in Marmara, Turkey (477 dialyzed) [5, 6], and Bam, Iran (106 dialyzed) [7], and Kashmir/Pakistan (55 dialyzed) [8, 9], the RDRTF provided clinical and dialysis support (table 1). In other disasters, only an assessment team was dispatched or advice was given $[8,10,11]$. All interventions are integrated into the medical activities of Médecins Sans Frontières (MSF; Doctors without Borders).

In this publication we describe the lessons learned and the characteristics, problems, and successes of the intervention of the RDRTF/ISN in Haiti, together with the nephrological implications of the Chilean earthquake.

\section{The Haitian Earthquake}

\section{Number of Expected AKI}

AKI in need of dialysis is expected after any major seism in a rapidly growing and densely populated urban area with constructions which are not necessarily earthquake-resistant [12]. From previous interventions it is known that specific circumstances influence the number of AKI occurring with each earthquake [9]. In the case of the Haitian disaster, many unknown factors made an appropriate prediction impossible.

On January 13, $10 \mathrm{~h}$ after the disaster, an assessment team from the RDRTF/ISN consisting of 1 nephrologist, 2 renal nurses, and 1 dialysis technician was dispatched from Europe [13]. The first team members arrived in Port-au-Prince on the morning of Friday, January 15, followed later on by several additional teams, all of which were parts of larger MSF groups.

\section{Local Medical Conditions}

Many major buildings, including hospitals, were severely damaged (fig. 1b) [14]. Hospital capacity in Portau-Prince was overwhelmed by the massive number of patients in need of treatment. The number of amputees amounted to at least 2,000 [15]. There were no functional facilities for basic laboratory measurements (e.g. potassium and creatinine), blood cultures, diagnostic imaging, or intensive care during the first weeks.

Before the earthquake, there were approximately 100 chronic hemodialysis patients treated in at least 4 units across Haiti. One unit was destroyed by the earthquake. No patients were on peritoneal dialysis.

The RDRTF/ISN assessment team found a partly intact dialysis unit in the University Hospital (HUEH Hôpital Universitaire de l'Etat d'Haïti) (fig. 3, 4a-d). Several other sections of the hospital had been destroyed (fig. 3). The unit was equipped with four 10-year-old dialysis machines (fig. 4b). A water softening and reverse osmosis system (fig. 4c, d) with a 200 -gallon storage tank (fig. 4e) distributed water into a loop with 9 connections. The general water delivery was cut off, as was the piping to connect the softeners (fig. 4c), but all of the RDRTF/ ISN teams included dialysis technicians who were able to repair the nonfunctioning dialysis machines and make the water treatment systems operational (fig. 4f).

While all other MSF teams worked in several other hospitals spread throughout the city, the nephrological team concentrated on the HUEH because of the preserved hemodialysis unit.

\section{Characteristics of the Dialyzed Population}

Overwhelming conditions made proper case registration and obtaining certainty about outcomes difficult.

In at least 30 patients with crush-related AKI in Portau-Prince, dialysis could be avoided by appropriate screening and fluid prevention. Another 27 patients with AKI needed dialysis and received a total of 117 hemodialysis treatments. Nineteen of these patients had AKI due to crush injuries, whereas 8 cases were not crush associated. Of the latter group, the majority was suspected to have had previous undiagnosed CKD mainly due to diabetes, hypertension, or HIV. Acute-to-chronic renal failure was in most cases precipitated by infection or stressrelated hypertensive crises. The age (mean $\pm \mathrm{SD}$ ) of the patients with crush-related AKI was $30 \pm 11$ years (range 16-58), while that of the patients with acute-to-chronic kidney disease was $37 \pm 16$ (range 15-55). The mean creatinine level before the first dialysis was $13.2 \pm 4.1 \mathrm{mg} /$ $\mathrm{dl}$ (range 8.1-20.0), blood urea nitrogen was $138 \pm 17 \mathrm{mg} /$ 

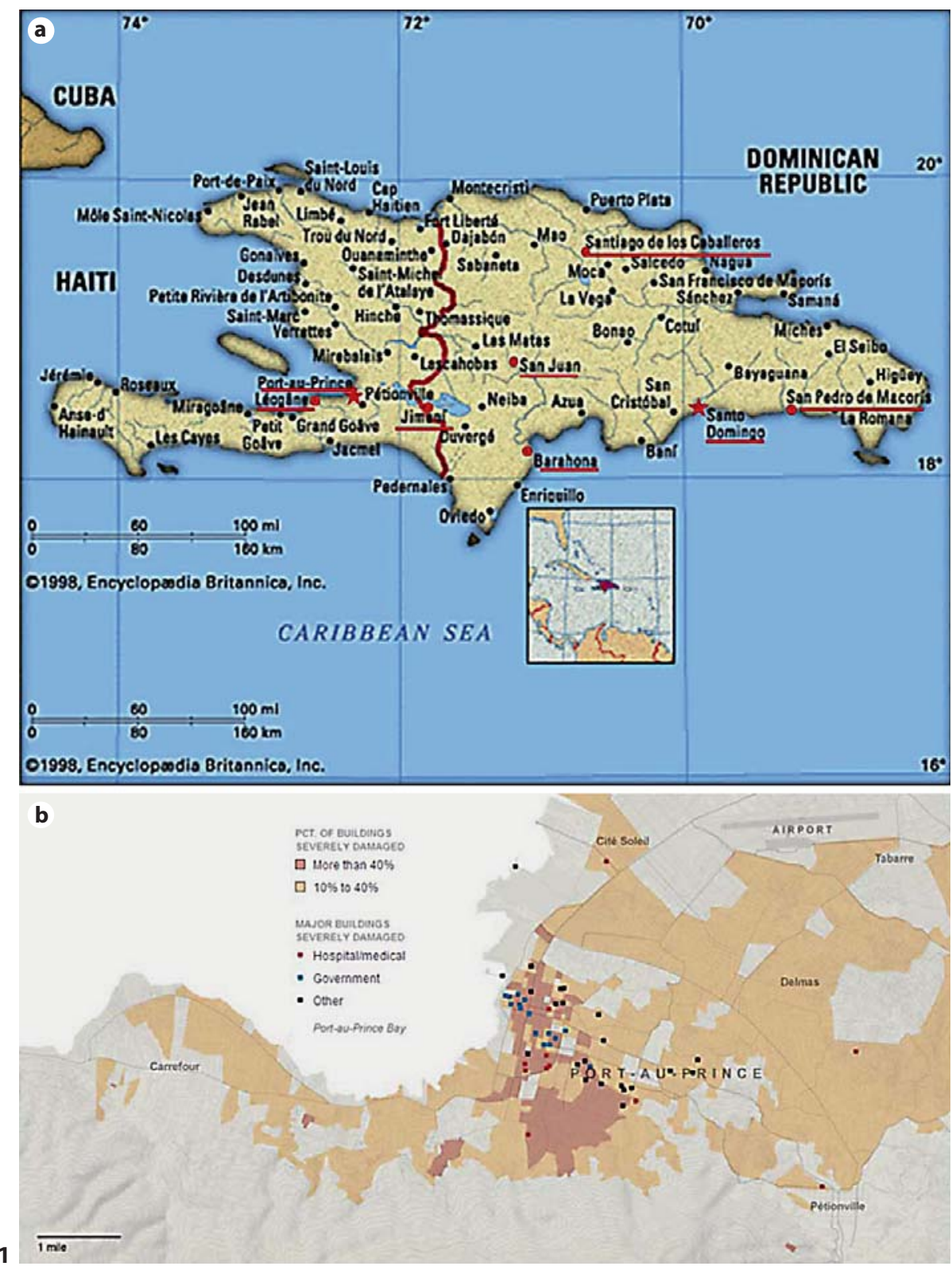

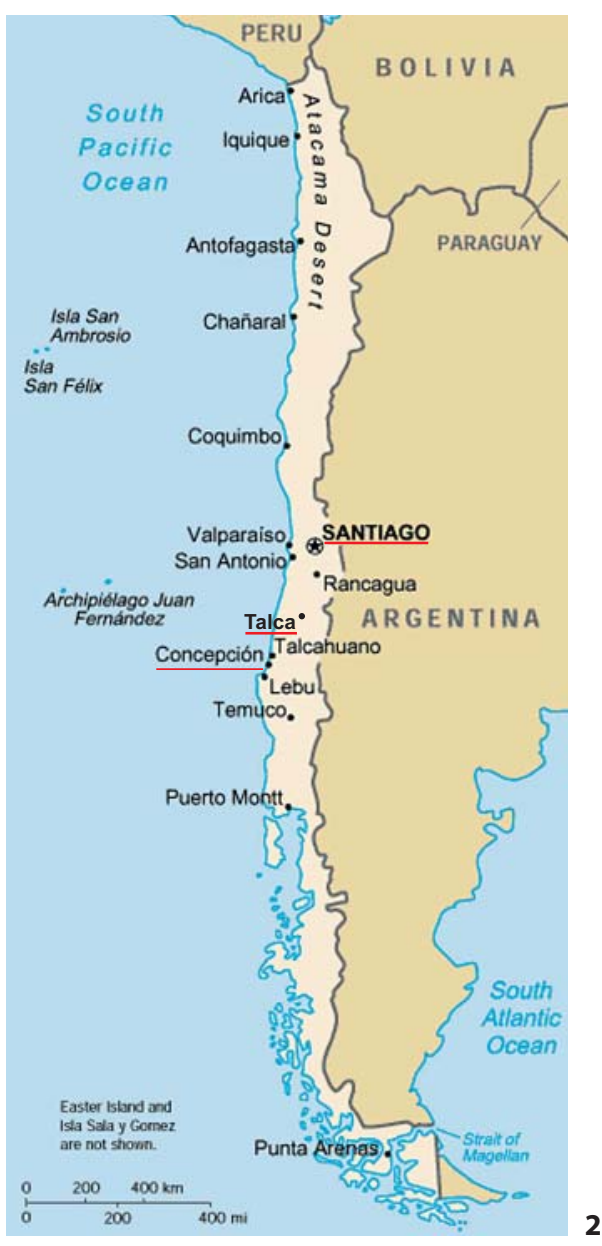

Fig. 1. a The geographic situation of the island of Hispaniola. Haiti is in the west, and the DR is in the east; the following cities are underlined: in Haiti, Leogâne (the epicenter) and Port-au-Prince (the highly affected capital); in the DR, Jimani and Barahona (border cities where the most important influx of victims from Haiti took place), and Santo Domingo, Santiago, San Pedro, and San Juan (where most of the dialysis activities took place). b City map of the metropolitan area of Port-au-Prince showing the damaged major buildings. The colored areas reflect severely damaged zones; light shade $=10-40 \%$ of buildings damaged; dark shade $=$ more than $40 \%$ of buildings damaged [14].

Fig. 2. Geographic situation in Chile. The following cities are underlined: Santiago de Chile (capital), and Concepción and Talca (the most affected cities). $\mathrm{dl}$ (range 105-140), potassium was $7.8 \pm 0.8 \mathrm{mEq} / \mathrm{l}$ (range $6.1-8.8$ ), and sodium was $125.0 \pm 3.8 \mathrm{mEq} / \mathrm{l}$ (range $119.0-130.0)$.

Five of the 19 patients with crush injuries were lost to follow-up overnight after their first dialysis; 4 of them very likely died. Another patient suffered from obstructive renal failure, was dialyzed once, and was then probably operated on, so it is conceivable that she recovered. Four patients were dialyzed and subsequently transferred to the USA hospital ship USNS Comfort for advanced 
Fig. 3. Google Earth image of the campus of the University Hospital (HUEH in Portau-Prince). The location of each of the buildings is indicated. The picture focuses on the dialysis unit in the center with the MSF Land Cruiser (white vehicle) parked outside. Some of the buildings were destroyed by the earthquake, e.g. the nursing school where more than 50 students were killed. The laboratory building was declared geologically unsafe. Patient care was in part delivered in tents (foreground).

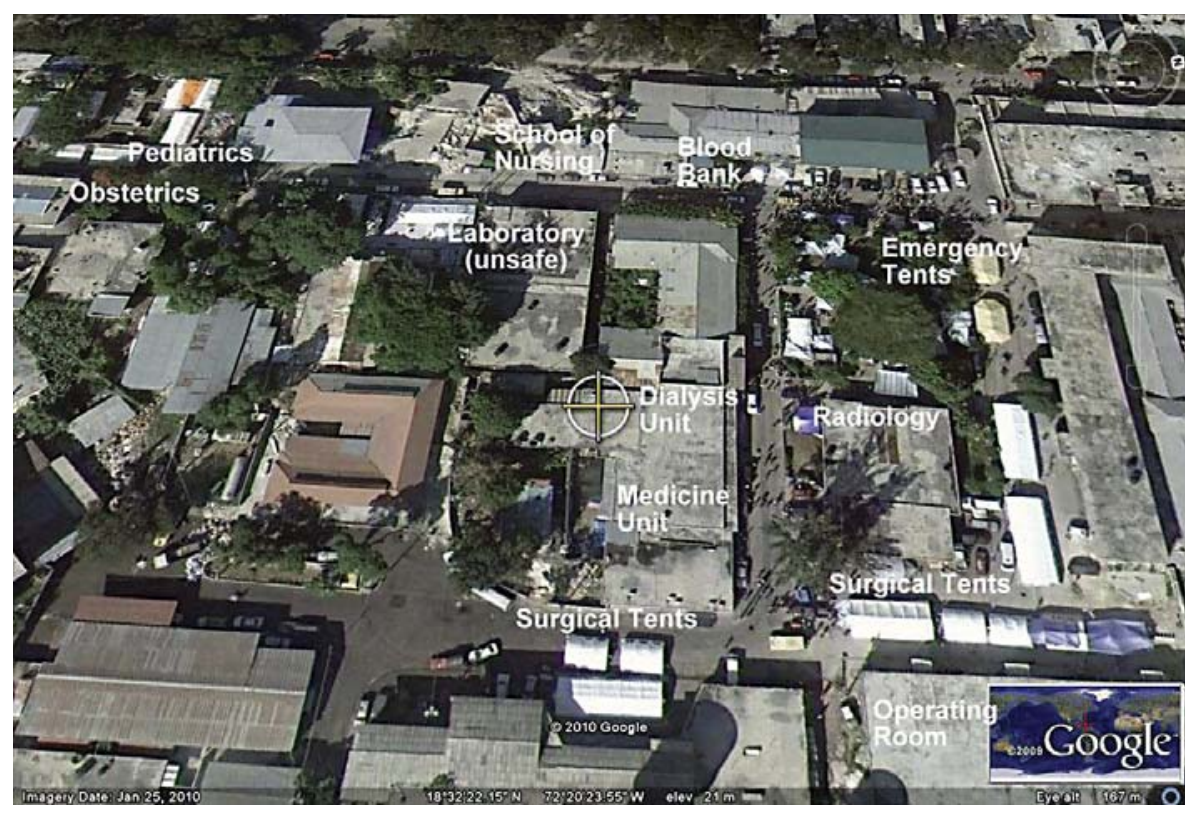

Table 1. Major interventions of the RDRTF [modified and adapted from 8, 10, 11]

\begin{tabular}{llll}
\hline Country & $\begin{array}{l}\text { Date } \\
\text { month/year }\end{array}$ & Disaster & Intervention \\
\hline Iran & $3 / 97$ & earthquake & \\
Moldova & $3 / 99$ & breakdown of dialysis stockpile & material support \\
Macedonia & $5 / 99$ & war & evacuation of chronic patients \\
Kosovo & $7 / 99$ & war & material support \\
Turkey & $8 / 99$ & earthquake & major intervention \\
Kosovo & $2 / 00$ & postwar conditions & educational support \\
India & $1 / 01$ & earthquake & assessment \\
Turkey & $5 / 03$ & earthquake & material support \\
Algeria & $5 / 03$ & earthquake & assessment \\
Iran & $12 / 03$ & earthquake & major intervention \\
USA & $8 / 05$ & hurricane & advisory role \\
Pakistan & $10 / 05$ & earthquake & major intervention \\
Poland & $1 / 06$ & collapse of sports hall & advisory role \\
Indonesia & $5 / 06$ & earthquake & assessment \\
Lebanon & $7 / 06$ & war/breakdown of stockpile & material support \\
Peru & $8 / 07$ & earthquake & assessment \\
Myanmar & $5 / 08$ & tornado & advisory role \\
China & $5 / 08$ & earthquake & major intervention \\
Italy & $4 / 09$ & earthquake & advisory role \\
Indonesia & $9 / 09$ & earthquake & assessment \\
Haiti & $1 / 10$ & earthquake & major intervention \\
Chile & $2 / 10$ & earthquake & advisory role \\
Turkey & $3 / 10$ & earthquake & advisory role \\
\hline
\end{tabular}



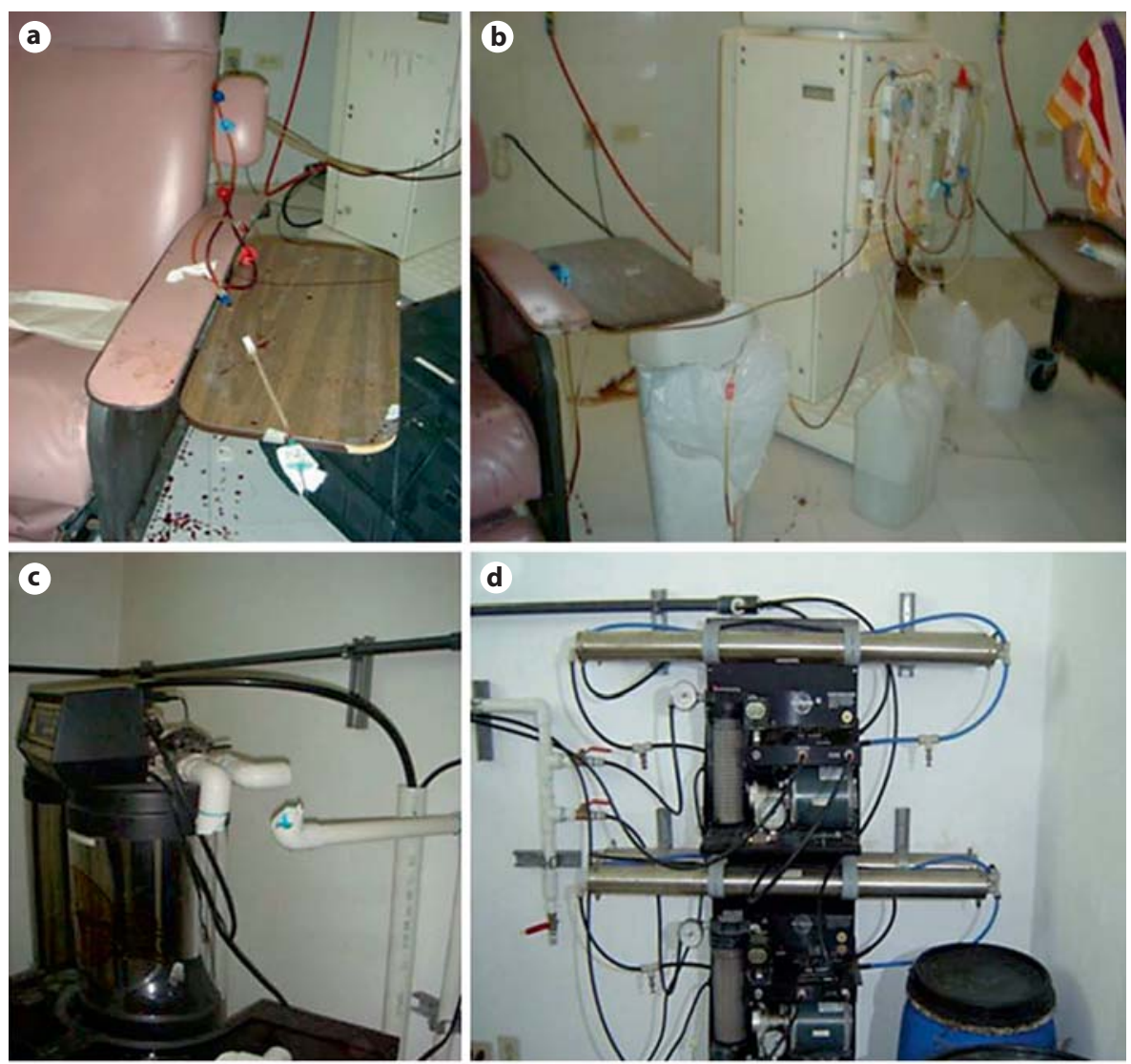

Fig. 4. Dialysis unit at the University Hospital (HUEH) in Port-au-Prince. a, b Dialysis infrastructure as found by the RDRTF-ISN assessment team upon their arrival; blood lines and filters were left in place by dialysis patients running out of the unit upon the occurrence of the earthquake. c-e Conditions of the water treatment system upon arrival. c Water softener with broken connectors. d Reverse osmosis system. e Previous 200-gallon water storage tank. f New water storage system installed by the RDRTF-ISN and MSF. Pictures are courtesy of P. Stockman, volunteer technician in the assessment team.
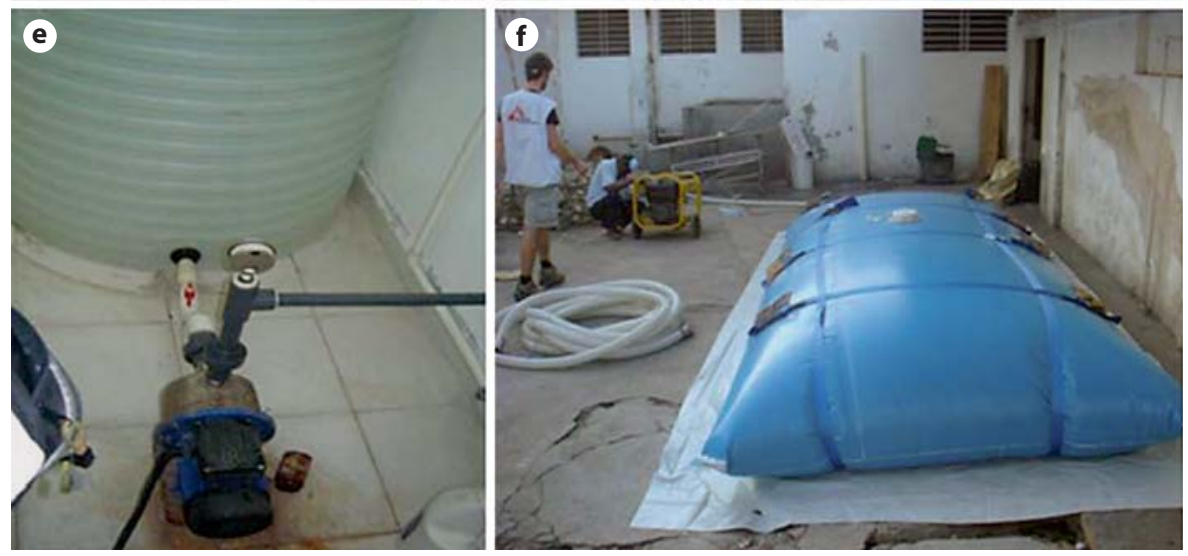

care. One patient with a delayed recognition of crush injury and AKI died during helicopter evacuation to Santo Domingo for critical care. All remaining patients survived and recovered renal function, confirming previous observations in larger populations [16]. Four patients required above-the-knee amputations. One of the 8 noncrush AKI patients died from respiratory failure and sepsis, another recovered kidney function after rehydration, and 6 remained on chronic dialysis when our intervention ended.
In addition, the RDRTF/ISN provided therapy to approximately 30 patients with chronic renal failure requiring dialysis at $\mathrm{HUEH}$, and provided the local dialysis nurses and technicians with education and support. The team also worked with the local nephrologists and vascular surgeons to optimize vascular access. No active search for CKD was undertaken to avoid overloading the dialysis unit with a number of patients largely in excess of the number prior to the disaster. Some chronic dialysis patients conceivably died in the earthquake or in the days 
Fig. 5. Transition among the different volunteers and teams. Red/grey $=$ Physicians; green/black = technicians; yellow/white = renal nurses. The left margin shows the nationalities. Although the intervention was planned to end on February 27, dialysis machines that had been ordered several weeks before to be dispatched from nearby Martinique were first withheld in Martinique and then at customs in Haiti; thus, an extra team consisting of 1 physician and 1 dialysis technician had to be enrolled. As a consequence, the mission ended on March 14, exactly 2 months after the departure of the first team. The length of intervention for each participant as presented here includes travel time, which totaled at least 4 days for most.

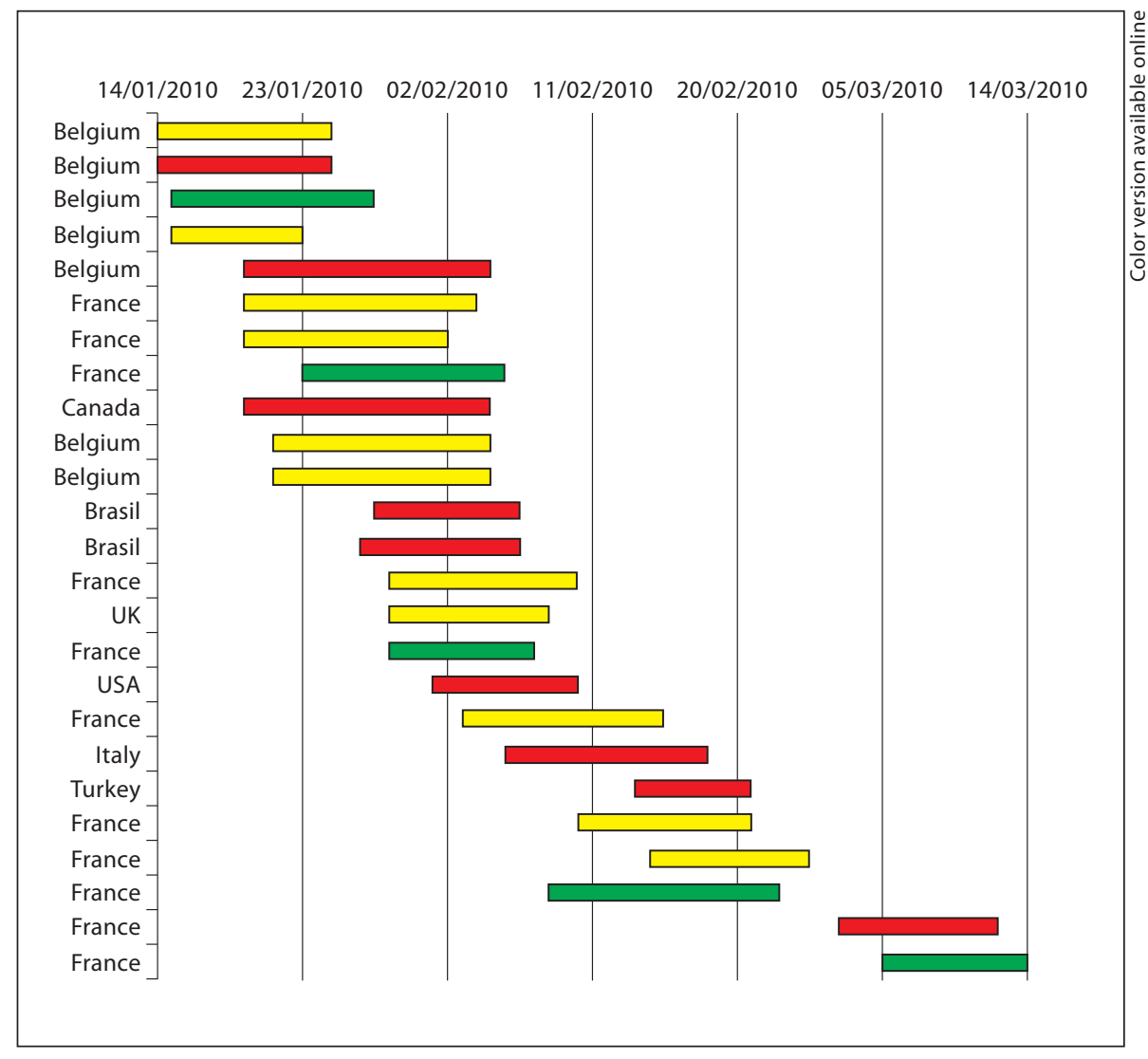

that followed or went abroad. A diaspora of chronic dialysis patients in the aftermath of disasters has been described in other events as well [17-19].

We are aware of a total of 32 Haitian crush patients with AKI who were dialyzed in the Dominican Republic (DR). Another 11 were managed conservatively. All but 1 survived and those who survived recovered kidney function.

The few additional AKI patients who were dialyzed on the USNS Comfort all recovered kidney function, as far as we know.

Assuming that all patients who were lost to follow-up died, the mortality of dialyzed crush victims in Haiti was $32 \%$, which is higher than in most other disasters $[7,8$, 11]. However, taking into account the patients in the DR as well, the mortality rate was $19 \%$, which conforms with the that of other disasters. It is likely that mostly patients in relatively better conditions were able to be moved to the DR. A similar improved survival rate with treatment performed at an increased distance from the epicenter was seen in other disasters $[2,20]$.

Response to the Haitian and Chilean Earthquakes of 2010

\section{Difficulties during Intervention}

\section{Logistics}

The harbor of Port-au-Prince was largely destroyed and the airport was too small to process the large number of people and the vast quantity of material. Both RDRTF volunteers and material entered the island via the DR. The volunteers initially travelled by road to Port-auPrince, necessitating an average travel time of 4 days back and forth in most cases, which took up to $66 \%$ of the total time of a mission. This situation made it necessary for the transition between teams to be anticipated well in advance (fig. 5).

The travel time for material was even longer. Three dialysis machines from the RDRTF/ISN that were dispatched on January 15 did not become available until January 20 because the aircraft carrying them was not able to land in Port-au-Prince airport before then [21]. Subsequently, material was imported from nearby Martinique, but this too was complicated due to customs issues and eventually increased the duration of the mission by 2 weeks (fig. 5). The easiest way to ship light material was in the hand luggage of new incoming rescuers.

Nephron Clin Pract 2011;117:c184-c197 

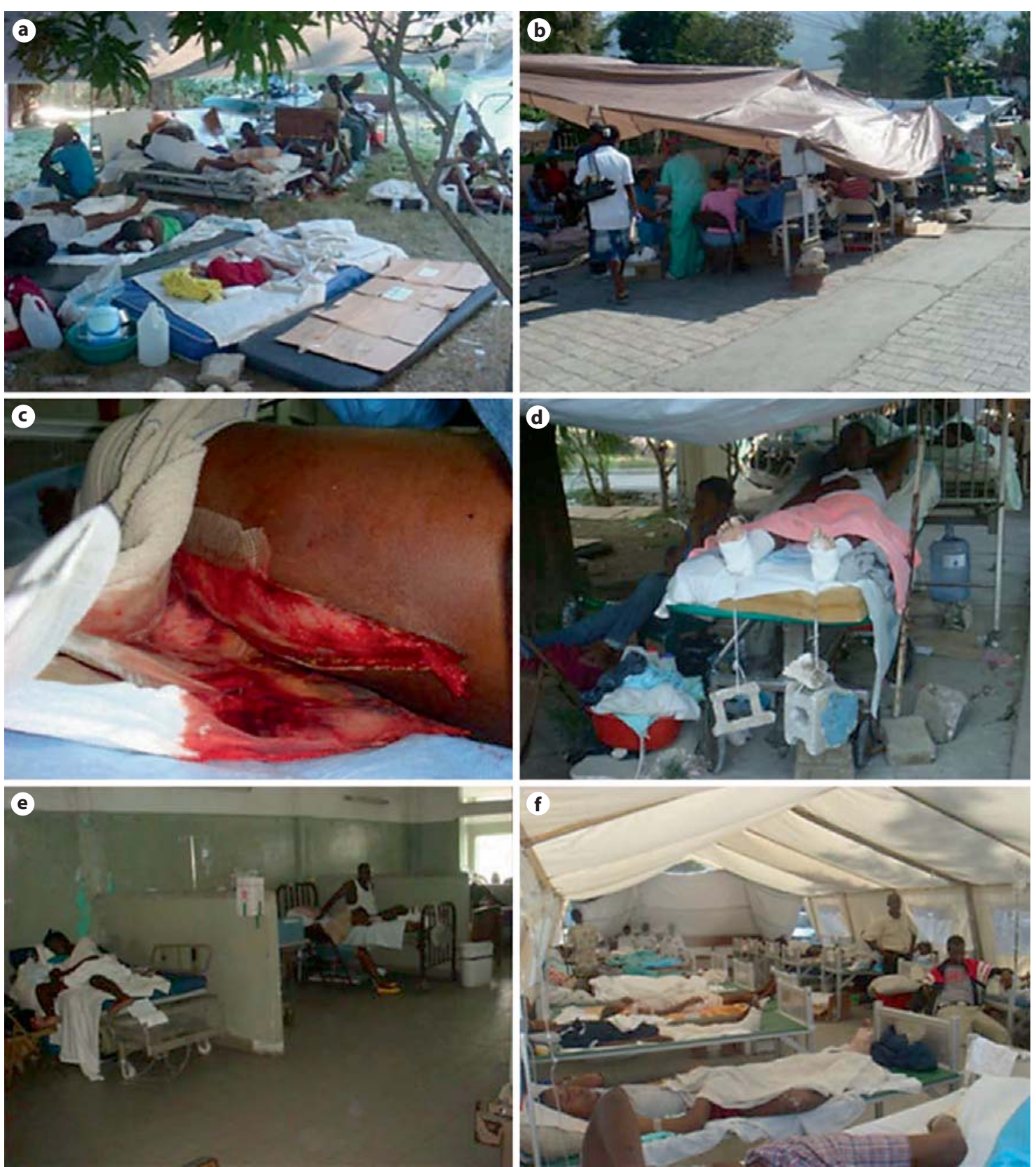

Fig. 6. Local conditions in Port-au-Prince in the first days after the disaster. a, b Wounded people lying outside in the open air. $\mathbf{c}$ Crush wound. $\mathbf{d}$, e In-hospital conditions. $\mathbf{f}$ A newly erected tent for medical care. Pictures are courtesy of S. Maddens, volunteer nurse in the assessment team.

Transport within Port-au-Prince was also heavily disrupted due to severe infrastructural damage, roads being blocked by movements of people and material, and initially, by corpses and wounded people lying in the streets (fig. 6a, b). This hampered missions for the screening of kidney function and communication with other hospi- tals treating potential AKI patients throughout the city, as well as centralization in the hospitals which were overcrowded and lacked sufficient material [22] (fig. 6d-f). Usually, open spaces serve as casualty collection points [23], but in Haiti almost all such areas were occupied by homeless people. 
Distribution of AKI Patients over Two Countries

Many wounded victims sought primary care along the border with the DR around Jimani and some were moved to Barahona, which is $1 \mathrm{~h}$ away from the border. From January 16 on, Haitian AKI patients were also treated in the DR (fig. 1a); the first dialysis occurred on January 18. The nephrological community in the DR was able to cope with this influx by benefiting from the material and advisory support of the Sociedad Latino-Americana de Nefrología e Hipertensión (SLANH), the American Society of Nephrology (ASN), and MSF. Dialysis was concentrated in Santo Domingo, Santiago, San Juan, Barahona, and San Pedro (fig. 1a).

Thus, of the nephrological communities involved with external support, the Disaster Relief Task Force (DRTF) of the ASN and the SLANH mainly concentrated on the DR, and the RDRTF/ISN focused on Haiti.

\section{A Chaotic and Unsafe Situation}

The usual approach of the RDRTF/ISN is to install a dialysis bridgehead outside the damaged zone $[5,8,24]$. During this disaster, RDRTF/ISN activities had to be organized in the damaged area; this allowed more contact with several surrounding hospitals with potential AKI cases, which was an advantage compared to our usual approach. Disadvantages, on the other hand, were less flexibility in terms of dialysis time frames and major safety concerns.

Chaos is present after almost every disaster, even when the event is predictable $[17,25]$. The situation in Port-auPrince remained chaotic and unsafe, especially at the beginning of the mission. As MSF had been working in the poorer areas of Port-au-Prince before the disaster, i.e. running a health center, a trauma unit, and a maternity hospital, their familiarity with these challenges was a major advantage.

The contribution of local nephrological nursing and medical staff could initially not cover the enormous needs. During the first days, the dialysis unit at HUEH was unmanned; approximately $80 \%$ of the hospital staff was homeless and living on the streets. In addition, in some facilities and for various reasons no nursing or medical surveillance was possible overnight.

\section{Shortage of Laboratory Facilities}

For 3-4 weeks there were no medical laboratory facilities in Port-au-Prince to measure essential biochemical parameters, reducing the capacity to detect AKI and its life-threatening electrolyte disturbances. In response, MSF supplied a new point-of-care device (i-STAT ${ }^{\circledR}, \mathrm{Ab}$ - bott, USA) with testing materials, and the RDRTF became the first rescue team to use such a device in the disaster zone. This was a major advantage since it permitted patient stratification into conservative management or dialysis in view of the scarcity of dialysis possibilities and of intravenous fluids for rehydration. The device was in high demand by other hospitals and NGOs, but can only operate within a limited temperature range. This obstacle was overcome quite soon by maintenance and transport in a cooled insulated container provided by MSF, permitting the use of the device in ambient temperatures of up to $35^{\circ} \mathrm{C}$. From then on, the i-STAT became a very useful device which allowed the RDRTF to assist other teams with the management of electrolyte imbalances and the monitoring of critically ill patients, e.g. diabetics with ketoacidosis.

Along the border with the DR, screening and triage were also hampered by a lack of laboratory reagents which became available only after 5 days. At a later stage, ASN donated 2 i-STAT machines to Haiti and another 2 to the DR.

\section{Communication Problems}

Initially, no contact with Haiti from the outside was possible. Subsequently, only limited exchanges via satellite telephone, SMS, and e-mail were possible, which sometimes required making important logistic decisions in spite of limited background information.

Communication was also limited within the disaster area. Although members of the RDRTF regularly visited several local and field hospitals for AKI screening and to create awareness regarding the dialysis possibilities, this information was often lost due to rotations in hospital teams and their leadership. In addition, it was impossible to reach all hospitals and rescue teams (at least 30 regular and field hospitals in total [26]). Cases of AKI were, therefore, missed [22].

Although central coordinating bodies like the Office for the Coordination of Humanitarian Affairs (OCHA) met daily with groups active in the field to disseminate information about practical possibilities, not all stakeholders were present at all of the meetings, and the information did not always seep down to the field workers. It is likely that regulatory bodies were also overwhelmed by the disproportionate number of victims as well as by heavy losses among their own ranks if, like the WHO or the UN, they were already present in Haiti before the disaster. 
Table 2. Distribution of the nationalities of volunteers

\begin{tabular}{llllc}
\hline Country & Nurses & MDs & Technicians & Total \\
\hline France & 5 & 1 & 4 & 10 \\
Belgium & 4 & 2 & 1 & 7 \\
Brazil & - & 2 & - & 2 \\
Switzerland & 1 & - & - & 1 \\
UK & 1 & - & - & 1 \\
Canada & - & 1 & - & 1 \\
Italy ${ }^{1}$ & - & 1 & - & 1 \\
USA & - & 1 & - & 1 \\
Turkey & - & 1 & - & 1 \\
\hline Total & 11 & 9 & 5 & 25 \\
\hline
\end{tabular}

MDs = Medical doctors.

${ }^{1}$ Italian citizen residing in Canada.

Table 3. Ratio of dialyzed patients/deaths $(\times 1,000)$

\begin{tabular}{lllc}
\hline Location & Country & Year & Ratio \\
\hline Spitak & Armenia & 1988 & $9.0-15.4$ \\
Northern Iran & Iran & 1990 & 3.9 \\
Kobe & Japan & 1995 & 24.6 \\
Marmara & Turkey & 1999 & 28.1 \\
Chi-chi & Taiwan & 1999 & 13.3 \\
Gujarat & India & 2001 & 1.7 \\
Boumerdes & Algeria & 2003 & 6.6 \\
Bam & Iran & 2003 & 3.7 \\
Kashmir & Pakistan & 2005 & 2.4 \\
Yogyakarta & Indonesia & 2006 & 0.7 \\
South of Lima & Peru & 2007 & 9.6 \\
Wenchuan & China & 2008 & 1.9 \\
L'Aquila $_{\text {Padang }}^{1}$ & Italy & 2009 & 29.3 \\
Port-au-Prince & Indonesia & 2009 & 0.0 \\
Maule & Haiti & 2010 & 0.2 \\
\hline
\end{tabular}

Reported numbers may be an underestimation of the reality.

${ }^{1}$ We are not aware of any dialyzed AKI patients in the recent Padang earthquake. DR.

${ }^{2}$ Considering dialyzed crush patients in both Haiti and the

\section{Lessons Learned}

Deployment of Personnel

The usual approach of the RDRTF is to deploy teams of doctors, nurses, and dialysis technicians. The teams in Haiti included proportionately more physicians than in previous missions (fig. 5; table 2) because of the initial emphasis on screening and prevention and, in a later phase, on teaching, e.g. how to place tunneled catheters.

The distribution of nationalities is illustrated in table 2. Three of the volunteers of French nationality were residents of nearby French overseas Caribbean departments (Martinique and Guadeloupe). Teams always contained volunteers with previous experience in RDRTF interventions and/or knowledge of French.

Due to the long travel times, the duration of each individual mission was longer than in most other interventions and lasted from 8 to 17 days. The total number of intervention days was 316 for 25 participants (average 12.6 days).

\section{Factors Influencing Patient Flow}

Comparing this disaster and its 222,517 deaths and 51 AKI patients with crush injuries to other disasters, we found that the prevalence of AKI was low (table 3). Several factors may have influenced this such as: the fact that it occurred during the day, when people are up and about, favoring head and chest trauma and decreasing the compression trauma to muscles; the presence of many buildings which were not sturdy enough to cause severe muscle trauma; difficulties encountered with early rescue; the extrication of most victims by neighbors or family members resulting in a selection of less heavily wounded people, and a lack of immediate medical help for the occasional severely affected victim. Specific to this disaster, mortality due to suffocation by the collapse of low-quality buildings, screening hampered by chaos, the lack of safety minimizing the possibilities of appropriate treatment $24 \mathrm{~h}$ a day, communication and logistic problems, and the availability of effective dialysis only until several days after the disaster, all added to the high mortality rate. Finally, preventive fluid resuscitation very likely kept several patients off dialysis.

The number of 51 dialyzed crush patients remains remarkable in view of the extreme conditions. It requires major efforts to start and maintain dialysis, so each saved life should be considered an accomplishment. Nevertheless, in better conditions the number of dialyzed AKI should have been higher.

\section{Intervention in Future Disasters}

This type of technological intervention is a challenge in an area with minimal infrastructure or with an excessive number of victims. In Haiti, both prevailed.

The RDRTF/ISN had to install what was essentially a de novo dialysis unit. Although a water treatment system and dialysis machines were present, both needed upgrad- 
ing and repair, while 9 additional machines were introduced to increase capacity. It is important to note that all of our teams included a dialysis technician, and that the mission would not have succeeded in providing a functioning unit without their assistance. Hence, worldwide advance volunteer recruitment must not be restricted to doctors and nurses; it should include dialysis technicians as well. What was accomplished is only 1 step away from creating an entirely new dialysis unit; based on the Haiti experience, this seems feasible. However, the long-term sustainability of such an intervention still needs to be proven.

Single-pass hemodialysis with sufficient dialysate flows remains the most desirable option in crush-related AKI because of: (1) sufficient solute removal, especially potassium; (2) limited cargo volume at transport, and (3) minimal bleeding risk. Alternative options have, to the best of our knowledge, not been demonstrated to perform as well on 1 or more of the 3 points listed above.

The RDRTF/ISN also focused on patient selection and fluid prevention. This aspect should be further optimized based on our current experience; in the future, a larger number of team members will be needed to work on this.

How this fluid prevention should be planned has been the topic of previous monographs [24, 27].

\section{Coordination and Communication}

Especially at the beginning of the intervention, there was no clear coordination of the different rescue actions due to difficulties sharing vital information among the different organizations on the ground. Teams in the field were not always aware of the dialysis possibilities in Portau-Prince. It is clear that better coordination and communication following a predefined intervention line are essential for efficacy.

Proactive incentives between disaster periods provided by the RDRTF/ISN, e.g. distributing information on their activities, are desirable. Instruction on the spot should include regular contact with primary care teams and nonnephrological staff regarding the usefulness of hydration and bicarbonate administration and the importance of avoiding nonsteroidal anti-inflammatory drugs and potassium-containing fluids (Ringer's lactate) in patients with suspected crush syndrome. There is a need for a consistent approach to prevent and treat crush syndrome and AKI, including fluid resuscitation. A panel of experts is preparing crush syndrome recommendations under the aegis of the ISN and European Renal Best Practice (ERBP), the guiding body of European Renal Association - Renal Dialysis and Transplantation Associa- tion (ERA-EDTA) [28]. Abbreviated versions and translations will be provided. On the occasion of the Haitian earthquake, preliminary versions were distributed and, for their use in the DR, translated into Spanish by the SLANH and the DRTF/ASN.

\section{Useless and Bulky Material}

The shipment of unrequested, useless material poses practical problems which are often underestimated by donors. Shortly after the disaster, the RDRTF received a donation of several thousands of liters of unrequested peritoneal dialysis (PD) fluid; this became known only when the whole shipment had been transported to Portau-Prince. PD in disaster circumstances is considered less useful due to inadequate potassium removal, and there were no chronic PD patients in Haiti. In spite of the best of intentions, this donation obliged MSF to transport, unpack, sort, store, and finally destroy tons of useless material. Hence, material donations should be limited to what is requested and should be coordinated with teams on the ground.

\section{The Chilean Disaster}

On Saturday, February 27, 2010, at 3.34 h local time (6.34 h GMT) the 8.8 Maule earthquake struck Chile; its epicenter was $115 \mathrm{~km}$ north northeast of Concepción, the country's second largest city (fig. 2). Reportedly, mortality was 507. It was classified as the 7th most severe earthquake of all times and the second most severe of this century (after the 2004 Sumatra-Andaman tsunami quake). Here as well, internal communication problems were substantial. Telephone contact with Concepción was possible only from Tuesday, March 2 on. Communication from abroad with Santiago de Chile, on the other hand, was efficient because of connection possibilities with the local contact person for the RDRTF/ISN who acted as a central link for nephrology and a liaison with the Chilean Health Ministry.

Almost all fatalities were attributable to drowning due to the occurrence of a tsunami and suffocation after the collapse of adobe houses. Crush injuries were rare. We are aware of only 2 dialyzed AKI patients, both of whom recovered kidney function. The low mortality rate and the low prevalence of crush injuries were largely attributable to the high standards of seismic construction in Chile.

The main renal problem in Chile was related to the more than 2,500 chronic dialysis patients who were treated in the damaged area. Whereas in the region 
Table 4. Recommendations to optimize interventions in difficult disaster circumstances

\section{- Avoid intervening \\ Without advance planning and intervention flow charts \\ On your own without being embedded in a larger \\ organization with experience in disaster intervention Without logistic support}

\section{- Avoid}

The shipment of material that has not been requested Logistic decisions resulting in bulky shipments Enrolling volunteers without advance selection and screening

- Enroll not only physicians but also nurses and technicians

- Pay attention to Screening for AKI and fluid prevention (if possible) Chronic dialysis patients on dialysis before the disaster

- Initiate interventions with an assessment team evaluating the local needs, if possible in consultation with representatives of the local nephrological community

- Try to arrive on the scene as soon as possible

- Look for existing infrastructure and try to repair it if it is damaged

- Plan sufficient overlap on the spot among your consecutive intervention teams so that essential information can be transferred among them

- Avoid an overly long duration of intervention per individual volunteer to avoid burnout

- Consider

Travel time as part of the intervention

Shipping light material in the hand luggage of new incoming volunteers

It is important to note that fully documented recommendations for disaster-related crush injuries, including their rationale, are currently being prepared by the RDRTF/ISN and ERBP. These recommendations are still under discussion among the different experts involved, and partially also depend on the upcoming Kidney Disease: Improving Global Outcomes (KDIGO) guidelines for AKI. What is recommended here is thus preliminary and might be presented differently in the final version of the recommendations.

around Talca problems could be solved by the reallocation of patients and machines, the situation in Concepción was more challenging due to more severe damage. Several dialysis units were originally out of order due to inadequate water distribution. Different scenarios for patient reallocation to areas outside the damaged zone were developed. Ultimately, $100 \%$ of chronic patients had access to dialysis by Friday, March 5 . This necessi- tated the reshuffling of patients and their schedules since by March 12 still only $60-70 \%$ of dialysis units were operational. The adaptation of the hemodialysis schedules of chronic dialysis patients appeared useful in previous disasters as well [19].

No international support was necessary.

\section{Conclusions}

No earthquake is comparable to another, and on site assessment by local or external experts is necessary to estimate nephrological needs. Preconceived intervention plans with a clear indication of everybody's role are essential to overcoming postdisaster chaos but are not always available [29]. The existing population on chronic dialysis should not be neglected in such plans or once an intervention is started.

The Haiti intervention made clear that it is possible to carry out dialysis rescue activities under extreme conditions. The Chilean earthquake revealed that internal redistribution may solve many problems if sufficient resources are available. In addition, the efficient organization of support and contact with the external world underscores the importance of local contact persons who should be appointed in advance by the local nephrological societies [29].

In view of the apparent discrepancies between the Haitian and Chilean interventions, with almost the entire focus on AKI in the first and on CKD in the latter, the response to each disaster should be titrated to the likely expectations in this regard. Defining these needs is the task of local and international intervention coordinators, in consultation with the assessment team, as also happened during the 2 disasters described in this publication.

It also appears that it is essential that this type of $\mathrm{Ne}$ phrology Task Force operates through a hands-on organization with good logistics such as MSF. In addition, the point-of-care device for the assessment of electrolyte and creatinine levels appeared to be a very useful tool and an essential piece of equipment for future similar disasters.

The number of dialyzed AKI patients in both disasters was low, but should be considered in the context of the local circumstances. None of the dialyzed patients in Haiti would have survived much longer without dialysis; however, the impact of our intervention could have been higher had a number of elements beyond our control been more favorable. The low number of AKI in Chile demonstrates that the careful implementation of appropriate ar- 
chitecture can play an important preventive role. In addition, both events were instructive for the future, i.e. with regard to organizing screening with point-of-care devices, fluid prevention, and affected dialysis units, as well as how to redistribute chronic dialysis patients.

For the first time several victims with acute-to-chronic renal failure were recorded, in line with observations in nondisaster populations [30,31]. Although the finding is new in disasters, it is conceivable that similar cases were already present in previous events although they were not registered. In the future, this possibility should certainly be taken into account in view of the apparently worse recovery perspectives for these patients than for those with crush-AKI.

A comprehensive list of recommendations (dos and don'ts) is given in table 4 . Since fully documented recommendations for disaster-related crush injuries are prepared by the RDRTF-ISN and ERBP, the present advice should be considered as preliminary and prone to modification.

\section{Appendix}

The functions of the authors were as follows: R.V. was the coordinator of the RDRTF of the ISN; D.B. was a volunteer renal nurse; S.C. was a volunteer nurse and a member of the assessment team of the RDRTF-ISN in Haiti; R.C.-R. was President of the SLANH; R.C. and M.C.F. were from MSF, Brussels, Belgium; N.G. and J.V. were volunteer physicians in Haiti for the RDRTF-ISN; A.H. was the Latin-American coordinator of the RDRTF-ISN; V.A.L. was a volunteer physician in Haiti for the RDRTF-ISN; D.P. was the coordinator of the DRTF of the ASN; S.R. was the president of the Nephrology Society of the DR; M.S.S. was the local Turkish coordinator for the RDRTF and a volunteer physician in Haiti for the RDRTF-ISN, and R.W. was the coordinator of the Renal Disaster Relief Force of the Chilean Society of Nephrology and the Chilean Government.

\section{Acknowledgements}

Interventions of this kind can only be accomplished with the help of many people. Coordination for MSF on the spot was done by R. Crestani (Italy) and L. Verhenne (Belgium). Coordination at the Brussels office of MSF was in the hands of M.C. Ferir (Belgium). Secretarial coordination at the RDRTF-ISN offices was done by C. Bergen (Belgium). Coordination of the recruitment of nurses and technicians was in the hands of A.M. Cadart (France) and S. Boule (Belgium). The Latin-American cell of the RDRTFISN was coordinated by A. Hurtado (Peru). The support of French volunteers from Martinique and Guadeloupe was highly appreciated, as well as the role of J.M. Dueymes as the contact in Martinique. Along the border with the DR, B. Jaar (USA) and O. Nuñez (DR) played an essential role in the screening and triage of crush- related AKI. Several companies donated dialysis equipment or point-of-care machines.

The following RDRTF-ISN volunteers participated in this mission: renal nurses D. Borniche (France), S. Claus (Belgium), V. De Preester (Belgium), H. Dunlop (UK), N. Eyhartz (France), S. Labbé (France), S. Maddens (Belgium), C. Martin (France), M. Paris (France), C. Peter (Switzerland), and M. Struelens (Belgium); physicians M. Augustin (France), R. Bueno de Oliviera (Brazil), R. Caluwé (Belgium), L. Fernandes da Silva (Brazil), N. Gibney (Canada), T. Imam (USA), S. Luyckx (Italy), M.S. Sever (Turkey), and J. Vanmassenhove (Belgium), and technicians B. Bonnet (France), H. Correia (France), J.P. Garcia-Perez (France), P. Stockman (Belgium), and M. Treffre (France).

In Haiti, surgeons from other medical teams assisted us with vascular access placement in chronic dialysis patients. We acknowledge R. Riviello (USA) and R. McCann (USA).

In addition to the RDRTF-ISN action in Haiti itself, extensive exchanges with other international nephrology bodies such as the ASN, the SLANH and the Société de Néphrologie took place. We appreciated the many useful discussions with the coordinator of the ASN DRTF D. Portilla and the president of SLANH R. CorreaRotter (Mexico). The ASN DRTF organized regular telephone conferences in which both the SLANH and the RDRTF-ISN participated. The help from colleagues from the DR, especially from the President of the Dominican Society of Nephrology S. Rodrigues (Santo Domingo), is also highly appreciated. The coordination in Chile between the government and the nephrological community was ascertained by R. Wainstein, appointed by the Chilean Society of Nephrology as coordinator to before the RDRTF-ISN.

More information on the activities of the RDRTF-ISN can be found on the ISN webpage at http://www.isn-online.org/isn/ index.html. The RDRTF-ISN can be contacted by e-mail at rdrtf@ugent.be. The Latin American contact person of the RDRTF-ISN can be reached at abdias.hurtado@upch.pe, and the contacts for Asia can be reached at vjha@pginephro.org and d.harris@usyd.edu.au. The DRTF of the ASN can be contacted at portilladidier@uams.edu.

References

1 Collins AJ: Kidney dialysis treatment for vic tims of the Armenian earthquake. N Engl J Med 1989;320:1291-1292.

-2 Sever MS, Erek E, Vanholder R, Akoglu E, Yavuz M, Ergin H, Tekce M, Korular D, Tulbek MY, Keven K, Van Vlem B, Lameire N: The Marmara earthquake: epidemiological analysis of the victims with nephrological problems. Kidney Int 2001;60:1114-1123.

-3 Vanholder R, Sever MS, Erek E, Lameire N: Rhabdomyolysis. J Am Soc Nephrol 2000;11: 1553-1561.

-4 Sever MS, Erek E, Vanholder R, Akoglu E, Yavuz M, Ergin H, Turkmen F, Korular D, Yenicesu M, Erbilgin D, Hoeben H, Lameire $\mathrm{N}$ : Clinical findings in the renal victims of a catastrophic disaster: the Marmara earthquake. Nephrol Dial Transplant 2002;17: 1942-1949. 
5 Vanholder R, Sever MS, De Smet E, Erek E, Lameire N: Intervention of the Renal Disaster Relief Task Force in the 1999 Marmara, Turkey earthquake. Kidney Int 2001;59:783791.

6 Erek E, Sever MS, Serdengecti K, Vanholder R, Akoglu E, Yavuz M, Ergin H, Tekce M, Duman N, Lameire N: An overview of morbidity and mortality in patients with acute renal failure due to crush syndrome: the Marmara earthquake experience. Nephrol Dial Transplant 2002;17:33-40.

$\checkmark 7$ Hatamizadeh P, Najafi I, Vanholder R, Rashid-Farokhi F, Sanadgol H, Seyrafian S, Mooraki A, Atabak S, Samimagham H, Pourfarziani V, Broumand B, Van Biesen W, Lameire N: Epidemiologic aspects of the Bam earthquake in Iran: the nephrologic perspective. Am J Kidney Dis 2006;47:428438.

$\checkmark 8$ Vanholder R, van der Tol A, De Smet M, Hoste E, Koc M, Hussain A, Khan S, Sever MS: Earthquakes and crush syndrome casualties: lessons learned from the Kashmir disaster. Kidney Int 2007;71:17-23.

-9 van der Tol A, Hussain A, Sever MS, Claus S, Van Biesen W, Hoste E, Khan S, Vanholder R: Impact of local circumstances on outcome of renal casualties in major disasters. Nephrol Dial Transplant 2009;24:907-912.

-10 Vanholder R, Stuard S, Bonomini M, Sever MS: Renal disaster relief in Europe: the experience at L'Aquila, Italy, in April 2009. Nephrol Dial Transplant 2009;24:32513255.

- 11 Vanholder R, Van Biesen W, Lameire N, Sever MS: The role of the International Society of Nephrology/Renal Disaster Relief Task Force in the rescue of renal disaster victims. Contrib Nephrol 2007;156:325-332.

-12 Vanholder R, Sever MS, Erek E, Lameire N: Acute renal failure related to the crush syndrome: towards an era of seismo-nephrology? Nephrol Dial Transplant 2000;15:15171521.

13 Vanholder R, Gibney N, Luyckx V, Sever MS: Renal Disaster Relief Task Force in Haiti eathquake. Lancet 2010;375:1163-1164.
14 The New York Times: Assessing the damage in Haiti. 2010. http://www.nytimes.com/interactive/2010/01/18/world/americas/0118haiti-assess-maps.html.

15 Bengele C: Haiti earthquake amputee numbers overstated, rehabilitation need substantial. 2010. http://www.associatedcontent. com/article/2643629/haiti_earthquake \%amputee_numbers_overstated.html.

-16 Sever MS, Erek E, Vanholder R, Koc M, Yavuz M, Ergin H, Kazancioglu R, Serdengecti K, Okumus G, Ozdemir N, Schindler R, Lameire N: Treatment modalities and outcome of the renal victims of the Marmara earthquake. Nephron 2002;92:64-71.

-17 Anderson AH, Cohen AJ, Kutner NG, Kopp JB, Kimmel PL, Muntner P: Missed dialysis sessions and hospitalization in hemodialysis patients after Hurricane Katrina. Kidney Int 2009;75:1202-1208

18 Kutner NG, Muntner P, Huang Y, Zhang R, Cohen AJ, Anderson AH, Eggers PW: Effect of Hurricane Katrina on the mortality of dialysis patients. Kidney Int 2009;76:760-766.

-19 Sever MS, Erek E, Vanholder R, Kalkan A Guney N, Usta N, Yilmaz C, Kutanis C, Turgut R, Lameire N: Features of chronic hemodialysis practice after the Marmara earthquake. J Am Soc Nephrol 2004;15:1071-1076.

20 Kuwagata Y, Oda J, Tanaka H, Iwai A, Matsuoka T, Takaoka M, Kishi M, Morimoto F, Ishikawa K, Mizushima Y, Nakata Y, Yamamura H, Hiraide A, Shimazu T, Yoshioka T: Analysis of 2,702 traumatized patients in the 1995 Hanshin-Awaji earthquake. J Trauma 1997;43:427-432.

21 Tran M: Airplane turned away from Hait airport, says medical charity. 2010. http:// www.guardian.co.uk/world/2010/jan/17/ haiti-quake-injured-hospitals.

22 Merin O, Ash N, Levy G, Schwaber MJ, Kreiss Y: The Israeli field hospital in Haiti ethical dilemmas in early disaster response. N Engl J Med 2010;362:e38.
23 Schultz CH, Koenig KL, Lewis RJ: Implications of hospital evacuation after the Northridge, California, earthquake. N Engl J Med 2003;348:1349-1355.

24 Sever MS, Vanholder R, Lameire N: Management of crush-related injuries after disasters. N Engl J Med 2006;354:1052-1063.

25 Kopp JB, Ball LK, Cohen A, Kenney RJ, Lempert KD, Miller PE, Muntner P, Qureshi N, Yelton SA: Kidney patient care in disasters: lessons from the hurricanes and earthquake of 2005. Clin J Am Soc Nephrol 2007;2:814824 .

26 http://www.reliefweb.int/rw/fullmaps am.nsf/luFullMap/24338419D7AD0A3685 2576BA00791D9A/\$File/map.pdf?OpenElement.

-27 Gunal AI, Celiker H, Dogukan A, Ozalp G, Kirciman E, Simsekli H, Gunay I, Demircin M, Belhan O, Yildirim MA, Sever MS: Early and vigorous fluid resuscitation prevents acute renal failure in the crush victims of catastrophic earthquakes. J Am Soc Nephrol 2004;15:1862-1867.

$>28$ Zoccali C, Abramowicz D, Cannata-Andia JB, Cochat P, Covic A, Eckardt KU, Fouque D, Heimburger O, McLeod A, Lindley E, Locatelli F, Spasovski G, Tattersall J, Van Biesen W, Wanner C, Vanholder R: European best practice quo vadis? From European Best Practice Guidelines (EBPG) to European Renal Best Practice (ERBP). Nephrol Dial Transplant 2008;23:2162-2166.

29 Sever MS, Lameire N, Vanholder R: Renal disaster relief: from theory to practice. Nephrol Dial Transplant 2009;24:1730-1735.

30 Hsu CY, Chertow GM, McCulloch CE, Fan D, Ordonez JD, Go AS: Nonrecovery of kidney function and death after acute on chronic renal failure. Clin J Am Soc Nephrol 2009; 4:891-898.

-31 Hoste EA, Cruz DN, Davenport A, Mehta RL, Piccinni P, Tetta C, Viscovo G, Ronco C: The epidemiology of cardiac surgery-associated acute kidney injury. Int J Artif Organs 2008;31:158-165.

\title{
Editorial Comment
}

\author{
Meguid El Nahas, Sheffield
}

Ray Vanholder and his colleagues of the Renal Disaster Relief Task Force (RDRTF) of the International Society of Nephrology (ISN) relate in this review their experience with the Haiti earthquake disaster. Their comprehensive report highlights a number of issues related to the provision of external renal support to the earthquake's victims, the lack of local infrastructure, as well as the expected chaotic situations relief agencies such as the Renal Disaster Relief Task Force (RDRTF) and Médecins Sans Frontières (MSF) work under. They also highlight the im- 
portance of aggressive fluid therapy to minimize acute kidney injury (AKI). In table 4, they have a comprehensive list of dos and don'ts that will form the basis of forthcoming formal guidelines. Perhaps an important challenge the RDRTF and ISN need to consider is an ongoing education and preparation program in areas and countries with a high earthquake risk; there is no substitute for a well-trained and organized local disaster relief force.
The task of providing external support and relief would be made so much easier if there were designated local coordinators trained by the ISN ready well ahead of any disaster. Prevention of AKI may be a neglected priority area. AKI prevention teams should be fostered in emerging countries such as Turkey, Iran, Haiti, and Chile, among others. One would hope that developed economies are better prepared. 